\title{
The application of Mongolian costume elements in modern fashion design
}

\author{
Yugang Chen ${ }^{1, a}$ \\ ${ }^{1}$ Jiangxi Institute of Fashion Technology, Jiangxi, Nanchang, 330201 \\ a28941204@qq.com
}

Keywords: Mongolian; Clothing elements; Modernization; Clothing design

\begin{abstract}
Mongolian costumes is an important part of Mongolian culture, in the clothing color, design, fabrics, modelling is more obvious, etc, these are often designers focus on and through the innovation characteristic element can be incorporated into clothing design. Based on the analysis of features of Mongolian costumes, elements and modelling aspects carries on the analysis, discusses the necessity of Mongolian dress element with the modern clothing fusion.
\end{abstract}

\section{The introduction}

Mongolian as one of the ancient nationalities in China, the dress culture has a long history, from ancient times to now every with rich dress culture characteristic of Mongolian nomadic life is referred to as the traditional Mongolian costume culture. Rise and fall of the Mongolian culture, Mongolian culture, at the same time it is also as the change of The Times and continuous development, the Mongolian national costume culture under the collisions with different times people demand gradually formed a unique, and can meet the demand of people's dress. Because of the Mongolian unique costume culture characteristics favored by more and more clothing designers, and applied to the garment design, in order to show the aesthetic feeling of national costumes and modern fashion fusion.

\section{The Mongolian costumes}

Mongolian nomadic is a routes and live in, because of its unique geography, geography and lifestyle, the main clothing hat, shawl, robes, belt, pants, leggings, boots and shoes, etc. Men's plain and simple, the integral atmosphere, women's noble gorgeous, elegant generous and line is clear. If on the clothing with different wear colorful, makes the Mongolian costumes free contracted anacreontic, there is no lack of again the aesthetic feeling of fine cut carved. Specific for traditional Mongolian costume has the following features:

Richness. Mongolian vast and numerous tribes and customs is more, the amount and type of clothing is natural number, all of these create conditions for the formation of its cultural diversity. Therefore, the Mongolian is more rich and colorful ethnic in national costumes.

Showily. Mongolian nomadic people, in the long nomadic life often moving, they are convenient to carry property, will the gold and silver jewelry and other precious jewelry to wear, it's added expensive gas for apparel, clothing become elegant.

Culture. Mongolian robes of needlework on design is with the national features and can show its unique geographical feature, folk custom all kinds of totem, colorful, exquisite workmanship, with distinctive national culture features.

Practicality. Mongolian costumes with strong performance, the robe is the Mongolian people often wear clothing, day and night during the day, its main cover decoration role, role to play in the cold night. Wearing thick and sturdy Mongolian boots can avoid mosquito bites and being thorns stabbed. Beam has constrictive waist belt to the outside of the hem of the robe, warm warm, protect internal in long time riding turbulence from damage.

\section{The Mongolian costumes elements}

Mongolian a old people in different historical stages have their own unique life habit, life style, in the evolution of history gradually formed the characteristics of their own clothing, richness, showily, 
culture, practicability and artistry, in addition, the style, fabric, such as edge and embroidery art design also has the unique feature. The following mainly the brief analysis of these elements in the Mongolian costumes.

Style elements. Mongolian costumes with robe is given priority to, its types are straight, even a sleeve, cloth, tunics and broken waist gown structure, as well as the different types of tank top and so on, these robe and tank top have in common is $\mathrm{H}$. The straight robe is similar to the planar structure of Chinese traditional clothing, before and after the rotator cuff location link, hypertrophy of sleeve structure, limited by fabric banners, before and after the centerline is patchwork. The del hem have loose and small amount of two kinds, put a straight hem smaller robe for ease of activities will be set under the fork, break the structure of the waist the del hem is relatively loose, the waist is gathers, activity rise more convenient also. The del overall modelling features easy and comfortable, design is characterized by simple and colorful.

Edge and embroidery elements. Edge is more traditional elements in the Mongolian costumes, mainly used for decorative collar, sleeve, cloth, hang jin, vents and, in areas such as the hem edge fabrics mainly has big velvet, silk, cotton, and different kinds of fur. Edge technology WuZhu MuQin robes are varied and colorful, because of age, generally USES the gown is three refers to the wide large pile or tinselled brocade edge, older people is given priority to with simple but elegant and comfortable gown, often set a refers to the wide black flocking or qdu. Chahar robes often at the edge of the cloth, collar band, led, cuffs, hem edge set with unilateral, and robe body with the edge of the corresponding color, especially young women's robes performance is more obvious. Aru khorchin furred robe on usually blue wide edge or big pile side wide, tinselled brocade edge silk robes. Mongolian embroidery art is unique, mainly with embroidery, applique, embroidery and so on, characterized by bright color contrast and adornment sex is strong, generally embroidered at the edge of the hem of the robe, cuff, cloth mouth edge, hats and boots.

The fabric material. Now use one of the most decorative materials in the Mongolian costumes for tinselled brocade, it is the use of polyester film and different metal layer of generic chemical fiber fabrics, compared with the traditional brocade, leather and cotton fabric is colourful, inexpensive, accord with modern fashion design standard, more can meet the demand of times development.

\section{The application of Mongolian costume elements in modern fashion design}

Example of national elements in modern fashion design is more, but how to reasonable use of unique national elements to modern clothing and make it to be in harmony is of particular concern for contemporary fashion designers. Need clothing designer in the process of using the national costume elements, for the selected national way of life, customs and habits, national psychology and other aspects in detail, the national cultural connotation and clothing element and modern fashion design needs together for clothing design.

The necessity of Mongolian costume elements with modern clothing fusion. With the continuous development of science and technology and the appearance of new materials, the design concept of the world's clothing have sprung up emerge in endlessly, national designer should design with the new wind, in the absorption and utilization of the essence of the traditional dress and advanced technology, based on the moment master fashion information, will expand national costume design, make the Mongolian costumes distinctive clothing features in the form of a fashion show in front of the public. Below is the Mongolian costume elements in modern fashion design application advantages are analyzed.

In the inheritance of the Mongolian characteristics on the basis of traditional dress element, to absorb the world fashion design concept, bold to design exaggerated in the local or national costumes characteristic element, make the design of clothing to the Mongolian costumes concise and easy, comfortable, atmosphere, the characteristics of leisure and fashion show. Such as, in on the basis of the Mongolian women robe hem elements of modern fashion design, can extract the dress and pleated skirt element, make the new design out the upper garment is cultivate one's morality, lower much more make public, to reveal the youthful vitality of young people. The cuff 
place of clothing can be combined with modern fashion trends to modify the original cuff, affix burrs fabric or lace, or the cuffs were exaggerated, to show young people the pursuit of freedom and dreams. In the design of modern tank top, can on the basis of the Mongolian waistcoat, absorb and draw lessons from denim jacket and the characteristics of bare midriff and its proper exaggeration shoulder, as a way of showing young people freedom, free and easy, natural and unrestrained.

The performance of the Mongolian costume elements in modern fashion design. Mongolian costume elements in modern fashion design examples of use is relatively small, from the point of use effect, the general can be divided into three aspects, one is on the basis of the Mongolian traditional costume design for processing production, again into the modern clothing design elements for modelling style, clothing after molding, people can see through clothing the Mongolian costumes elements; The second is the modern T taichung exaggerated use of Mongolian costumes elements in bright colors, will be the charm of the Mongolian wild ruggedly show in the form of clothing in the clothing; Three is applied to clothing, leather garments and leather boots elements with fashionable dress fabrics mix together, reveals the modern clothing. A domestic clothing brand fashion show in the process, green dust coat selection is peculiar to the Mongolian national costumes belt and button elements, green silk fabric cuff, girdles and pockets are embroidered with Mongolian characteristic of totem, in all of the dust coat dignified luxuriant and at the same time, can also shows the elegance of Mongolian costumes. Clothing masters Jeremy Scott clothing works selected is barr tiger Mongolian hair accessory elements as clothing design elements, he first to deformation of the original Mongolian hair, then bold use of Mongolian commonly used red and orange and as the main tonal for design, it makes the nomadic unique wild displayed at the same time, will also modern clothing fashion information.

\section{Conclusion}

Mongolian costumes element in modern clothing made some achievements, the application designer to Mongolian unique costume culture and modern fashion design technique and combine the demand of people, design of clothing to a certain extent can satisfy people's demand for beauty and fashion, can also be indirect characteristics of Mongolian culture. But with the development of The Times and social progress, people will be more demand for clothing, need designers combine the present needs, from Mongolian and other ethnic costumes made more elements used in the clothing design, will be further popularized the Mongolian costume culture, let more people know and understand the Mongolian culture, understand the Chinese traditional culture.

\section{Reference}

[1] Gao Jie. The Mongolian costumes of the "old" elements "new" application [J]. Journal of research of art, 2011. (11) : 134-135.

[2] Wu Ritu. Collision of traditional culture and fashion - talk about the evolution of modernization of Mongolian costumes [J]. Journal of observatory of fine arts. 2014 (3) 117-118.

[3] Xia Meng. China's traditional costume and fashion combined with the exploration of [D]. Tianjin university of science and technology, the design of art, 2010.03. 